\title{
CAMBRIDGE Mathematics
}

\section{A Primer of Nonlinear Analysis}

\section{A. AMBROSETTI}

This is an introduction to nonlincar functional analysis, in particular to those methods based on differential calculus in Banach spaces and is intended to accompany upper division courses for students of pure and applied mathematics and physics.

f25.00 net HB $0521373905192 \mathrm{pp}$.

\section{Vortex Dynamics}

\section{P. G. SAFFMAN}

The emphasis in this monograph is on the classical theory of inviscid incompressible fluids containing finite regions of vorticity. Including chapters on viscosity, compressibility, inhomogeneity and stratification, this book will be an invaluable guide for researchers in hypersonic flight to fluid mechanics.

f 35.00 net HB $052142058 \times \quad 336 \mathrm{pp}$. Cambridge Monographs on Mechanics and Applied Mathematics

\section{Wave Asymptotics}

Edited by P. A. MARTIN and G. R. WICKHAM

The papers collected here outline the development of fluid mechanics and asymptotics, and will be valuable reading to all who are interested in water waves and asymptotic techniques.

$£ 22.95$ HB $0521414148 \quad 250 \mathrm{pp}$.

\section{Large Eddy Simulation of Complex Engineering and Geophysical Flows} BORIS GALPERIN

Large eddy simulation (LES) is one of the most powerful computational tools available today for studying complex rurbulent flows. Galperin provides a comprehensive review of LES - the history, state-of-the-art, and promising directions for future research.

f50.00 net HB 0521430097550 pp.

\section{Bénard Cells and Taylor Vortices}

\section{E. L. KOSCHMIEDER}

Describes the research done on the problems of Benard convection, as well as its modern offspring the RayleighBénard problem, and Taylor vortices. Both problems are classical examples in the theory of hydrodynamic stability and share many features.

f35.00 net HB 0521402042288 pp.

\section{Acta Numerica 1993}

\section{A. ISERLES}

This year's Acta Numerica presents six invited papers on a broad range of topics from numerical analysis. Papers treat each topic at a level intelligible by any numerical analyst from graduate student to professional.

f22.95 net HB $0521443563 \quad 323 \mathrm{pp}$.

\section{Turbulence and Random Processes in Fluid Mechanics}

Second Edition

\section{T. LANDAHL and E. MOLLO-CHRISTENSEN}

This timely update continues the original theme of the book, presenting the fundamental concepts and basic methods of fluid flow turbulence, enabling the reader to follow the literature and understand the current research. f30.00 net HB 052141992 i 170 pp. f12.95 net $P B \quad 0521422132$

\section{Topics in Fluid Mechanics}

RENE CHEVRAY and JEAN MATHIEU

The authors have aimed for simplicity in presentation, stressing physical understanding over mathematical development. Specialized subjects such as chaotic advection, chaos and the onset of turbulence are given particular attention.

f65.00 net $H B \quad 0521410827 \quad 384 \mathrm{pp}$.

f27.95 net $P B \quad 0521422728$

\section{Lectures on Ergodic Theory and Pesin Theory on Compact Manifolds}

\section{MARK POLLICOTT}

Pesin theory consists of the study of the theory of nonuniformly hyperbolic diffeomorphisms. The author provides us with a straightforward account of this theory, following the approaches of Katok and Newhouse. f19.95 net PB 0521435935180 pp.

\section{The Quantum Theory of Motion} PETER HOLLAND

This is the first comprehensive exposition of the interpretarion of quantum mechanics pioneered by Louis de Broglie and David Bohm. Written in a clear and concise manner this book will appeal to all physicists with an interest in the foundations of their subject. $\$ 70.00$ net $\mathrm{HB} \quad 0521354048 \quad 624 \mathrm{pp}$.

To order any of these books 'phone our 24 hour credit card line on 0223325970 or write to Joann Motherwell at the address below. 
Submission of manuscripts Papers may be submitted to any member of the editorial board. Three copies should be sent; originals of figures should not be included until the paper has been accepted. Upon acceptance of a paper, the author will be asked to transfer copyright to the publisher. Papers may be submitted electronically by sending a LaTeX file to EJAM@VAX.OX.AC.UK; this file should include the figures (line figures only). Electronic communications can also be used for minor corrections and for messages to the editors.

Layout of manuscripts Papers should be typewritten in double spacing throughout, on one side of the paper. Please avoid footnotes if possible. Papers must begin with an abstract of not more than 300 words, and they should end with a brief concluding section. The SI system of units must be used throughout. There is no formal restriction on length, but the constraint of fitting an integral number of papers into 96 pages means that short papers (20 typed pages or fewer) are likely to appear sooner than the long ones.

Illustrations Figures should be drawn in indian ink on good quality white paper or produced by computer to comparable quality. Wherever possible they will be reproduced with the author's lettering. A list of captions for figures should be attached separately.

Where appropriate, articles may be illustrated by photographs : high-quality glossy black and white prints are necessary.

References References should be listed in alphabetical order at the end of the main text. Please include the article title in the reference, which should be in the order: author's surname, initials; year in parentheses; article title; journal name, abbreviated in accordance with the World List of Scientific Periodicals (4th Edn); volume number (underlined); inclusive page numbers.

Citations in the text Any unambiguous system is acceptable. Three recommended ways of citing a 1992 paper by A. European are: European (1992); European [Eu]; European [7]. In the second case, the reference at the end of the text should be preceded by [Eu], and in the third by [7]. Please note that in the third system, alterations may lead to wholesale renumbering.

EDITORIAL POLICY

The European Journal of Applied Mathematics aims to publish papers in all areas of applied mathematics, with especial emphasis on the following.

(i) The exposition of new mathematical ideas relevant to the modelling and analysis of modern technological processes.

(ii) The development of interesting mathematical methods with broad areas of applicability.

There is no restriction in the areas of applicability or the style of mathematics as long as the content is presented so as to be as accessible as possible to the entire community of mathematicians and mathematical scientists. This applies in particular to the introductory section of the paper. Standard mathematical techniques will only be published if they are associated with novel applications or lead to substantial advances in established problem areas.

COPYING

This journal is registered with the Copyright Clearance Center, 27 Congress Street, Salem, MA 01970. Organisations in the USA who are also registered with the C.C.C. may therefore copy material (beyond the limits permitted by sections 107 and 108 of US copyright law) subject to payment to C.C.C. of the per-copy fee of $\$ 5.00$. This consent does not extend to multiple copying for promotional or commercial purposes. Code 0956$7925 / 93 \$ 5.00+.00$

Organisations authorised by the Copyright Licensing Agency may also copy material subject to the usual conditions.

ISI Tear Sheet Service, 3501 Market Street, Philadelphia, Pennsylvania 19104, USA, is authorised to supply single copies of separate articles for private use only.

For all other use, permission should be sought from the Cambridge or the American Branch of Cambridge University Press.

(C) Cambridge University Press 1993

CAMBRIDGE UNIVERSITY PRESS

The Pitt Building, Trumpington Street, Cambridge CB2 1RP

40 West 20th Street, New York, NY 10011-4211, USA

10 Stamford Road, Oakleigh, Melbourne 3166, Australia 


\section{European Journal of}

Applied Mathematics

\section{VOLUME $4 \cdot$ PART $3 \cdot$ SEPTEMBER 1993}

\section{CONTENTS}

A mathematical model of damage accumulation taking into account microstructural effects

G. I. BARENBLATT and V. M. PROSTOKISHIN

Cardiac magnetic resonance imaging by retrospective gating: mathematical modelling and reconstruction algorithms

J. B. T. M. ROERDINK and M. ZWAAN

On the analysis of brine transport in porous media

C. J. VAN DUIJN, L. A. PELETIER and R. J. SCHOTTING

Decay estimates of solutions for a hybrid system of flexible structures

B. RAO

Printed in Great Britain by the University Press, Cambridge

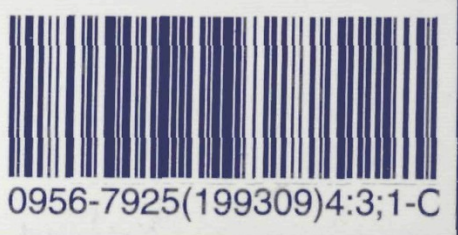

